\title{
Summer Dreams
}

\section{Veranja Liyanapathirana}

Monsoon rains

Have come and gone

Quintessential

Remnants of summer

Rambutans and durians

Discarded peels

Bustles with activity

Lives of other kinds

Wriggling and swimming

Summer dreams

Of warm humid nights

Fanning away the creatures of nature

That annoying bustle of wings

Of lives that emerged from the discards

Creatures of nature

That fly in search of meals

Meals of red

Within the meal

Enveloped

In a protective sheath

Lies a being

Is it alive or is it not?

We argue in the summer's heat

How to define life?

This being is a villain

A villain of a kind

Minute yet mighty

Astute and elusive

Adapting and evolving

\section{Acknowledgment}

Thanks to Samanthika Abeywickrama for the inspiration.

This poem was inspired by an online conversation with Dr.

Abeywickrama and the dengue epidemic in Sri Lanka in 2017.

Dr. Liyanapathirana is a senior lecturer at the Department of Microbiology, Faculty of Medicine, University of Peradeniya,

Sri Lanka. Her research interests are antimicrobial resistance and pneumococcal epidemiology.

Address for correspondence: Veranja Liyanapathirana, Department of Microbiology, Faculty of Medicine, University of Peradeniya, Peradeniya, Sri Lanka; email: veranjacl@pdn.ac.lk

Author affiliation: University of Peradeniya, Peradeniya, Sri Lanka

DOI: https://doi.org/10.3201/eid2310.171117 